\title{
A UTILIZAÇÃO DE Phragmites australis (Reeds) COMO BIOMASSA: UM ESTUDO DE VIABILIDADE PARA A INSTALAÇÃO DE UM SISTEMA DE COGERAÇÃO OU SISTEMA DE AQUECIMENTO DISTRITAL PARA A VILA DE COTTOWN, ESCÓCIA.
}

\author{
M. T. B. BOLDARINI ${ }^{1}$, I. G. BRANCO ${ }^{1}$, A. L. VIEIRA ${ }^{1}$, L. F. de LIMA $^{1}$ \\ ${ }^{1}$ Universidade Tecnológica Federal do Paraná, Campus Londrina \\ E-mail para contato: mtbboldarini@gmail.com
}

\begin{abstract}
RESUMO - Com o crescente consumo de energia e a necessidade de investir em opções de energia renovável, foi realizado uma análise sobre a possível utilização de Phragmites australis, uma planta encontrada nas margens do rio Tay- Escócia, como fonte de energia para a vila de Cottown, localizada no nordeste da Escócia. Esta vila conta com 47 casas, e até o presente momento queima óleo como fonte de aquecimento das mesmas. Buscando utilizar uma fonte renovável de baixo custo, realizou-se um estudo sobre a biomassa próxima ao local, verificando seu potencial calorifico, sua disponibilidade e a viabilidade de sua utilização como matéria prima. Tendo em mente o contexto apresentado acima, o presente trabalho estuda também a possibilidade de troca do atual sistema de aquecimento da vila de Cottown pelo aquecimento distrital, que pode ser utilizado apenas para calefação ou aproveitado em um sistema de cogeração de energia.
\end{abstract}

\section{INTRODUÇÃO}

Energia é fundamental para a vida humana e um acesso seguro a mesma é essencial para a manutenção das sociedades modernas. A demanda energética vem crescendo e a necessidade de buscar fontes alternativas de energias, sejam estas térmica ou elétrica, mostrase cada vez mais relevante. Uma das grandes motivações desta busca deve-se ao fato de que combustíveis fosseis, além de serem recursos não renováveis, são os responsáveis pelo aumento do efeito estufa e chuvas ácidas, já que durante a sua queima ocorre a liberação de dióxidos de carbono e outros gases nocivos para a atmosfera (Shamsuzzoha et al., 2012).

A partir do Ato de Mudanças Climáticas de 2008, onde estabeleceu-se objetivos mundiais a serem atingidos em relação as mudanças climáticas, o Departamento de Energia e Mudanças Climáticas do Reino Unido traçou metas para a redução das emissões de gases causadores do efeito estufa em pelo menos $80 \%$ até o ano de 2050. Para atingir os objetivos algumas estratégias foram criadas: reduzir a demanda energética, aumentar a eficiência energética e investir em tecnologias de baixa emissão de $\mathrm{CO}_{2}$. Desta maneira fontes de 
energia renovável podem ter um papel significativo na ajuda ao Reino Unido, para que o país possa atingir seus objetivos de redução de emissão de gases nocivos.

Segundo Dermibas (2004), o uso de biomassa é uma alternativa prática e de baixo custo para fornecer calor e ser utilizado no sistema de calefação e aquecimento de água e vapor em Sistemas de Aquecimento Distrital. Essa mesma biomassa pode ser utilizada em Sistemas de Cogeração de Energia, fornecendo calor para o aquecimento interno das residências e ao mesmo tempo produzir energia elétrica. O sistema de cogeração tem sido considerado uma das principais alternativas para substituir os sistemas tradicionais de aquecimento com economia de energia e auxiliando na preservação ambiental.

Em países como África, Índia, China, Espanha, Alemanha e Dinamarca já se encontram vilarejos ou pequenas cidades que utilizam apenas fontes renováveis de energia para suprir suas necessidades elétricas e/ou de aquecimento, assim, esses locais que buscam que $100 \%$ de sua energia utilizada seja renovável são denominados de Eco - Vilas. Porém, as fontes de energia variam entre solar, eólica, biomassa, marés ou até mesmo a utilização de duas ou mais fontes para suprir suas demandas e, em alguns casos, sendo possível armazenas ou vender o excedente energético (Ericsson, 2004).

Considerando o exposto, o objetivo do presente trabalho é uma análise térmica da utilização de Phragmites australis (Reeds) como matéria prima para a produção de vapor e energia elétrica na Vila de Cottown, localizada no nordeste da Escócia, visando transforma-la em uma Eco - Vila, ou seja, que $100 \%$ de sua energia utilizada seja proveniente de uma fonte renovável.

\section{METODOS E RESULTADOS}

Cottown é uma vila situada entre Dundee e Perth, na Escócia (Reino Unido). A vila está localizada as margens do rio Tay, o que significa uma grande disponibilidade da biomassa em estudo, uma vez que a região é a mais rica em plantações de Reeds de todo o Reino Unido. Atualmente a vila conta com uma população de 138 habitantes distribuídos em 47 residências.
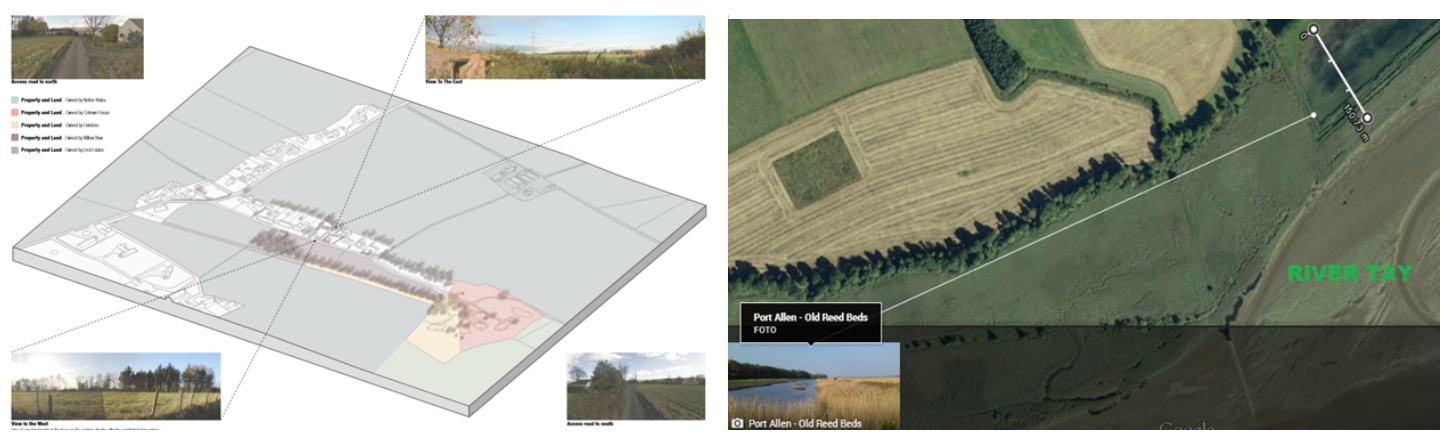
A metodologia aplicada visa verificar a viabilidade de implementação de um sistema de aquecimento e/ou cogeração para toda a vila, utilizando a biomassa Phragmites australis, segundo as seguintes etapas:

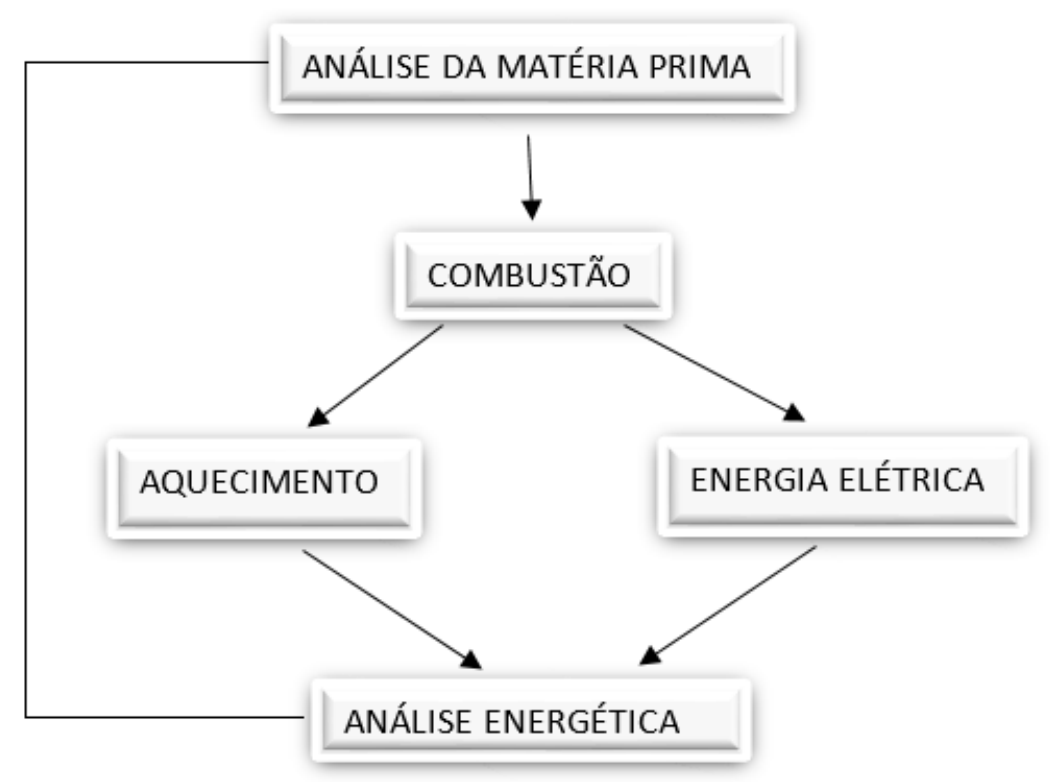

\subsection{Análise da Biomassa}

A análise da biomassa buscou a melhor relação entre custos e viabilidade energética da planta pois foi previamente estabelecido que, a energia fornecida para o aquecimento da vila de Cottown derivaria da combustão de matéria prima. Quando escolhido o Phragmites australis como fonte de energia, alguns aspectos da planta foram considerados, tais como: a mistura da massa do Reed, o poder calorifico (PCI) e a densidade do material.

O Phragmites australis ou popularmente conhecido no Brasil como junco, é encontrado em regiões temperadas por todo o mundo. São hastes lenhosas rígidas e ocas, que possuem aproximadamente 2,54 cm de diâmetro e podem crescer de 1,5 até 4 metros de altura. Esta gramínea é encontrada em águas salobras, águas doces e zonas de grande humidade, crescendo próximos ou até mesmo sobre a água (Tucker, 1990).

Verificou-se que, para a aérea de estudo, a utilização Phragmites australis como biomassa possui uma relação de custo benéfico bastante vantajosa, uma vez que o Reeds é abundante e naturalmente disponível na região e, de acordo com o Chichester Harbour Conservancy (2006), os canaviais de junco cresceram principalmente no leste da Inglaterra. Até 2006, a maior área registrada fica situada na Escócia, no estuário do rio Tay, com uma área de cerca de 410 hectares. Além disso, seu corte é essencial para a manutenção da vida silvestre, pois a plantação de Reeds serve como berçário para espécies nativas, obrigando o governo a realizar a colheita anualmente. 
Estudos realizados pela Martti Komulainen et al. (2008) provou que o uso de Reeds para substituir a queima óleo (derivado de petróleo) contribui com a redução de gás carbônico liberado na atmosfera, auxiliando no objetivo traçado pelo Reino Unido em 2008. De acordo com o mesmo estudo, um hectare de Phragmites australis utilizado como biomassa no processo de aquecimento residencial substitui aproximadamente 2 mil litros de óleo que seriam utilizados para a mesma finalidade, ou seja, seriam 2 mil litros de óleo que deixariam de ser queimados, reduzindo a emissão de $\mathrm{CO}_{2} \mathrm{em}$ aproximadamente 6 toneladas.

\subsection{Combustão da biomassa}

A reação de combustão é frequentemente utilizada no caso de biomassa solida em função do baixo custo e alta eficiência. Caracteriza-se como poder calorífico de um combustível (PC) a energia liberada pela sua combustão e, pode ser mensurada pelo poder calorifico superior (PCS) e inferior (PCI). Os dois tipos de poder caloríficos se diferenciam pela fase que se encontram os produtos ao final da combustão, sendo que o PCI caracteriza-se por todos os produtos em fase gasosa (inclusive a água) enquanto o PCS por todos os produtos em fase gasosa (com exceção da água, que apresenta-se em fase líquida) (Petro Energia Industrial 2014).

Segundo Hiss Reet apud Simionescu (1966), a biomassa escolhida para o presente estudo possui a composição química descrita na Tabela 1. Esses valores serão utilizados para os cálculos de PCI e PCS.

Tabela 1: Composição média do Phragmites australis

\begin{tabular}{|c|c|c|c|c|}
\hline Celulose & Lignina & Carboidratos & $\begin{array}{c}\text { Água, gorduras e } \\
\text { resina }\end{array}$ & $\begin{array}{c}\text { Substâncias } \\
\text { Minerais }\end{array}$ \\
\hline $42,51 \%-45,04 \%$ & $22,09 \%-23,88 \%$ & $23,88 \%-27,217 \%$ & $1,15 \%-5,63 \%$ & $4,72 \%-5,63 \%$ \\
\hline
\end{tabular}

A partir da análise proximal foi possível realizar o cálculo do PCI em função equação de Mendeleev, o que resultou em um valor médio de $14 \mathrm{MJ} / \mathrm{kg}$.

Segundo a Martti Komulainen et al. (2008), o Reed possui baixa densidade, variando entre $20 \mathrm{a} 60 \mathrm{~m} / \mathrm{kg}$. Como visto na Tabela 1, a planta estudada possui uma alta concentração de celulose, fator este que propicia a produção de fuligem e, ainda segundo BIOMASS Energy Centre (2013), quando queimado o Reeds isoladamente, em função do seu alto poder calorifico (14 MJ/kg), pode ocorrer um superaquecimento dos fornos.

Portanto visando diminuir a produção de fuligem e minimizar os possíveis problemas causados pela baixa densidade e alto poder calorifico da matéria prima, Kitzler et al. (2012) sugerem que o Phragmites australis seja queimado em uma proporção de 50\% da biomassa com $50 \%$ de briquetes de madeira sem que haja qualquer prejuízo para a alimentação da caldeira nem para o incinerador. 


\subsection{Aquecimento e Geração de Energia Elétrica}

Sistemas de bioenergia em pequena escala são considerados propícios quando instalados em vilarejos e pequenas cidades, uma vez que, estes sistemas possuem baixo investimento de instalação podendo suprir as necessidades térmicas e elétricas do local.

A tecnologia termoquímica tem a capacidade de converter a biomassa em energia térmica (geração de vapor) ou elétrica, pelo acionamento de turbinas (energia mecânica). Ainda, a produção simultânea das duas formas de energia é considerada como cogeração.

Máquinas térmicas são os aparelhos que transformam energia interna de um combustível em energia mecânica, ou de forma mais simples, equipamentos capazes de converter calor em trabalho (Bornakke e Sonntag, 2010). A utilização do ciclo Rankine é a proposta idealizada mais adequada para máquinas térmicas a vapor, onde semelhante a máquina de Carnot, o sistema é constituindo pela caldeira (transferência de energia entre a energia gerada na combustão e a água), a turbina (conversão de energia térmica em mecânica), condensador e bomba que viabilizam o processo cíclico (Fernandes, Pizzo e Moraes Jr., 2006).

Segundo Marting (2004), a eficiência média considerada para o processo de geração de vapor através de Rankine é de $20 \%$ para processos de aquecimento de água e $30 \%$ para sistemas de cogeração. Outro parâmetro considerado é de que os campos Reeds tem uma produção estimada em 5 toneladas por hectare por ano (Komulainen et al., 2008).

\subsubsection{Demanda de Aquecimento}

Atualmente a energia necessária para aquecer as residências situadas na vila de Cottown é proveniente da queima de óleo. Segundo o Governo Escocês, para estimar o valor em kWh de energia foi adotado o percentual de $80 \%$ do total de energia consumida.

Segundo as estatísticas fornecidas pelo Governo Escocês (2006), o consumo elétrico diário de uma casa pode ser adotado como sendo $12 \mathrm{kWh} /$ dia, assim, supõe-se que a demanda elétrica é de $4380 \mathrm{kWh} /$ ano por casa. Considerando que a média de energia elétrica consumida por uma residência na vila é de $4380 \mathrm{kWh} /$ ano e que esse valor representa $20 \%$ do total de energia consumida, é possível calcular que a demanda de calor é de $17520 \mathrm{kWh} / \mathrm{ano}$ por casa. Analisando toda a vila, a demanda de calor deve ser multiplicada pelo número total de casas pertencentes a Cottown, com isto, temos que a energia total para aquecimento é de $823440 \mathrm{kWh} /$ ano.

Utilizando-se de $50 \%$ de Reeds $(\mathrm{PCI}=14 \mathrm{MJ} / \mathrm{kg})$ e $50 \%$ briquete $(16 \mathrm{MJ} / \mathrm{kg})($ Quirino et al., 2005) calculou-se a necessidade de aproximadamente 106 hectares de Reeds e 456 toneladas de briquete ao ano. 


\subsubsection{Demanda Elétrica e Térmica (Cogeração)}

Assumindo que a eficiência total do processo de 30\% e considerando a utilização da biomassa com $50 \%$ de Reeds $(\mathrm{PCI}=14 \mathrm{MJ} / \mathrm{kg})$ e $50 \%$ briquete $(16 \mathrm{MJ} / \mathrm{kg})$ (Quirino et al., 2005) os cálculos demostram a necessidade de aproximadamente 88 hectares de Reeds e 380 toneladas de briquete ao ano.

\subsection{CONCLUSÃO}

Os cálculos apresentados durante o trabalho, foram realizados para verificar a viabilidade energética e ambiental de instalação de um Sistema de Cogeração de Energia, ou apenas de Aquecimento Distrital.

Com o presente estudo foi possível constatar a grande disponibilidade energética encontrada nas plantações de Phragmites australis, situadas às margens do rio Tay na Escócia. Verificou-se que a biomassa adotada apresenta grande potencial de combustão, apresentando um alto poder calorifico o que estimula a sua utilização como matéria prima.

Em função da proximidade da vila de Cottown com os campos de Reeds (distância estimada de $5.5 \mathrm{~km}$ ) e, apesar da baixa densidade da matéria prima estudada, existe uma facilidade no transporte da biomassa, não apresentando um aumento significativo no custo de corte e transporte, apesar do grande volume necessário da planta.

Por fim, concluiu-se que o Sistema de Cogeração de Energia, apesar de um maior custo de instalação por possuir turbina e outros maquinários, seria o melhor processo energético para a vila já que para uma produção de energia mais eficiente utilizou uma menor área de plantação, sendo necessário menos de 2 hectares por família por ano.

Este estudo desperta sobre a possibilidade de utilização macrófitas (juncos) como matéria prima para a produção de energia em pequenas comunidades brasileiras, possibilitando uma maior diversidade nas fontes de energia elétrica e térmica no país.

\subsection{REFERÊNCIAS}

BORNAKKE C.; SONNTAG R. E., Fundamentos de Termodinâmica. São Paulo: Edgard Blucher, 2010.

BIOMASS ENERGY CENTRE. Grants and support, 2011. Disponível em: $<$ http://www.biomassenergycentre.org.uk/portal/page?_pageid $=77,15133 \&$ dad $=$ portal \&_schema=PORTAL\#SUPP $>$. Acesso em: 02 ago. 2014.

DEMIRBAS, A., Combustion characteristics of different biomass fuels. Prog Energy Combus Sci, 2004. 
ERICSSON K., Bioenergy policy and market development in Finland and Sweden, pp. 17071721, 2004.

FERNANDES, F. A. N., PIZZO, S. M.; MORAES Jr D., Termodinâmica Química. UFC. 2006. Disponível em: <www.eq.ufc.br/MD_Termodinamica.pdf $>$. Acesso em: 10 de nov. 2014.

KITZLER, H., PFEIFER, C.; HOFBAUER, H., Combustion of reeds in a $3 \mathrm{MW}$ district heating plant. International Journal of Environmental Science and Development, 2012.

KOMULAINEN M.; SIMI P.; HAGELBERG E.; IKONEN I.; LYYTINEN S., Reed energy: Possibilities of using the Common Reed for energy generation in Southern Finland. 67. ed. Turku: Saarijarven Offset Oy, 78 p. (67), 2008. Disponível em: $<$ http://julkaisut.turkuamk.fi/isbn9789522160355.pdf>. Acesso em: 15 jul. 2014.

MARTINS, O. S., Aproveitamento da Biomassa para a Geração de Energia Elétrica. Brasília: Centro Nacional de Referência em Biomassa, 2004. 31 slides, color.

PETRO ENERGIA INDUSTRIAL. http://www.petroenergia.com.br/coque.html. Acesso em: 10 de ago. 2014.

HISS REET. Chemical characteristics of water reed, 2006. Disponível em: <http://www.hissreet.com/knowledge/water-reed-characteristics.html>. Acesso em: 05 mar. 2015.

SHAMSUZZOHA A.H.M.; GRANT A., CLARKE J., Implementation of renewable energy in Scottish rural area: a social study, Renewable and Sustainable Energy Reviews, 16 (1), pp. 185-191, 2012.

SILÉN, H., The possibilities of harvesting the Common Reed for bio energy and construction use on the coastal area of Southern Finland. Bachelor's thesis, Turku University of Applied Sciences, Sustainable Development, 2007.

GOVERNO ESCOCÊS, The department of Energy \& Climate change, Disponível em: $<$ https://www.gov.uk/government/organisations/department-of-energy-climate-change>, Acesso em: 15 nov. 2014.

TUCKER, G. C., The genera of Arundinoideae (Gramineae) in the southeastern United States. Journal of the Arnold Arboretum 71:145-177, 2010. 